\title{
Perforation Rates of Cervical Pedicle Screw Inserted from C3 to C6 - A Retrospective Analysis of 78 Patients over a Period 5 of 14 Years -
}

\author{
Jun Takahashi, Hiroki Hirabayashi, Hiroyuki Hashidate, \\ Nobuhide Ogihara, Keijiro Mukaiyama, Syuugo Kuraishi, \\ Masayuki Shimizu, Masashi Uehara and Hiroyuki Kato \\ Department of Orthopaedic Surgery, Shinshu University School of Medicine, \\ Matsumoto-City, Nagano, \\ Japan
}

\section{Introduction}

Cervical spine fixation using cervical pedicle screw (CPS) was first reported by Abumi [1] and Jeanneret [2] in 1994. Both reports described cases of cervical instability caused by cervical trauma. Cervical spine fixation by CPS was introduced as a procedure for the cervical instability of middle and/or lower cervical spine caused by trauma, and the importance of fixation by CPS for posterior cervical decompression and reconstruction was later reported $[3,4]$. Cervical pedicle screws can achieve rigid fixation compared to other cervical pedicle fixation methods [5, 6], and enable posterior cervical cord decompression. However, cervical pedicle screw insertion is technically demanding because of the narrow pedicle diameter and the risk of serious neurovascular complications including vertebral artery tear, spinal cord injury, and nerve root injury [7]. To achieve more accurate and safe pedicle screw insertion, navigation by two-dimensional imaging system or CT has been employed in recent years [9-12]. However, CPS insertion from C3 to C6 is technically demanding. The purpose of this study was to evaluate the perforation rates and direction of screw perforations in these insertions using CT-based navigation system.

\section{Materials and methods}

We evaluated 78 subjects (49 men and 29 women; mean age, $61.1 \pm 14.2$ years) who had undergone CPS insertion from C3 to C6 by using a CT-based navigation system from September 1997 to March 2011. A frameless stereotactic image-guidance system (StealthStation and Stealth Station TREONTM; Medtronic, Sofamor Danek, Memphis, TN, USA) was used in screw placement and fixation of the cervical spine. The profile of cervical pedicle screw system was as follows; SUMMIT SI Occipito-cervico-thoracic (OCT) spinal fixation system (Depuy Spine, Inc., Raynham, MA), Olerud cervical system (Nord Opedic, Askim, Sweden), RRS Loop Spinal System (Robert Leid, Tokyo, Japan), Vertex Max system 
(Medtronic, Sofamor Danek, Memphis, TN, USA) , Axon system (Synthes, Inc., West Chester, PA, USA), and Oasys (Optimal Aignment System) (Stryker Spine Allendale, NJ, USA).

\section{Pedicle screw insertion technique assisted with navigation system}

The basic data used for navigation were preoperative CT scan imaging data, consisting of consecutive axial slices $1 \mathrm{~mm}$ in thickness of the patients. The data were transferred to the system computer and were reconstructed into two-dimensional (2-D) and three-dimensional (3-D) images on a video monitor. Other mechanical components consisted of a computer workstation, a surgical reference frame, a probe rod to indicate the position in the surgical field, infrared light-emitting diodes (LEDs) that were attached to the probe rod, an electrooptical camera as a position sensor connected to the computer, and a drill guide. Infrared beams were tracked by the electro-optical camera system and the position of the respective LEDs was identified in real time in the surgical field.

Registration was performed in order to accurately match the computer-reconstructed 3-D surgical space with the real surgical space, by identifying four or more points on the vertebrae and the corresponding points of the vertebrae on the 3-D CT image on the monitor (matched-pair point registration). Though more precise matching of the two spaces is usually obtained by repeated registration procedures with 30 or more randomized points indicated by the probe on the surface of the vertebral body (surface registration), this group's procedure employs only 5 to 6 registration points for two consecutive lamina, to shorten the surgical time. More accurate positioning is possible by using the top of the spinous process and bilateral inferior facet caudal tip as points.

We established a surgical plan a day before surgery and confirmed insertion point of screws, applicability of $3.5 \mathrm{~mm}$ screws, point-for-point registration, screw position in relation to vertebral artery. This planning procedure took 20 to $40 \mathrm{~min}$. Evaluation during the surgical plan for navigation provides further benefit by identifying pedicles with insertion risks and excluding such pedicles from operation (about $10 \%$ of all pedicles were excluded). Then, the entrance holes, direction, diameter, and depth of the screws were depicted with a cursor on the monitor, and the surgery was initiated. After exposure of the posterior bony elements of the spine, the reference frame was fixed to the spinous processes and the registration procedures described above were performed. After completion of the registration by matched-pair point and surface registration, the screws were inserted under the guidance of the navigation system. The position of the probe or drill guide was superimposed in realtime on CT images on the monitor, and the screws were introduced into the pedicles at the planned position indicated on the monitor. The required time between fixation of reference frame to spinous process and insertion of pedicle screw to each segment ( 1 or 2 vertebrae) was 10 to $15 \mathrm{~min}$. After all screws were set, the reference frame for registration was removed and additional surgical procedures including decompression or bone graft were followed. If pedicle screw insertion was ineligible, sublaminar cable fixation by SecureStrand was performed.

Diseases included 22 cases (16 males, 6 females; mean age $52.2 \pm 18.8$ years) of spinal trauma, 19 cases (8 males, 11 females; mean age $65.0 \pm 8.9$ years) of rheumatoid arthritis (RA), 13 (7 males, 6 females; mean age 69.9 \pm 7.6 years) of cervical spondylotic myelopathy (CSM), 11 (7 males, 4 females; mean age $65.2 \pm 7.0$ years) of destructive spondyloarthropathy (DSA), 6 (4 
males, 2 females; mean age $62.3 \pm 9.1$ years) of spine tumor, 5 cases (4 males; mean age $53.6 \pm 15.2$ years) of cervical spondylotic myelopathy associated with athetoid cerebral palsy $(\mathrm{CP})$, and 2 ( 2 males; mean age $45.5 \pm 10.6$ years).

Using postoperative axial $\mathrm{CT}$, the screw insertion status was classified as follows: grade 1 (no perforation), screw is accurately inserted in the pedicle; grade 2 (minor perforation), perforation of less than $50 \%$ of screw diameter; grade 3 (major perforation), perforation of $50 \%$ of screw diameter or more. The directions of perforations were evaluated as well.

The data were analyzed by a paired-sample Student $t$ test using SPSS (SPSS Japan Inc., an IBM company, Tokyo, Japan), with $\mathrm{p}<0.05$ defined as significant.

\section{Results}

Mean surgical time was $239 \pm 109$ (range; 90 - 505) minutes. Mean blood loss volume was $352 \pm 327$ (range; 20 - 1500) grams. For grade 3 (major perforation), the screw perforation rates by vertebral level were as follows: C3 (4/65, 6.2\%), C4 (5/65, 7.7\%), C5 (2/68, 3.1\%), and C6 (1/76, 1.3\%); therefore, higher perforation rates were observed for C4 and C3. For grade 3 and grade 2 , the screw perforation rates by vertebral level were as follows: $\mathrm{C} 3$ $(12 / 65,18.5 \%), C 4(14 / 65,21.5 \%), C 5(15 / 68,22.1 \%)$, and C6 (8/76, 10.5\%); therefore, higher perforation rates were observed for C5, C4, and C3, in this order (Fig. 1). For all the screws, the major perforation rate (only grade 3$)$ was $4.4 \%(12 / 274)$ and perforation rate (grade 3 and grade 2 ) was $17.9 \%(49 / 274)$.

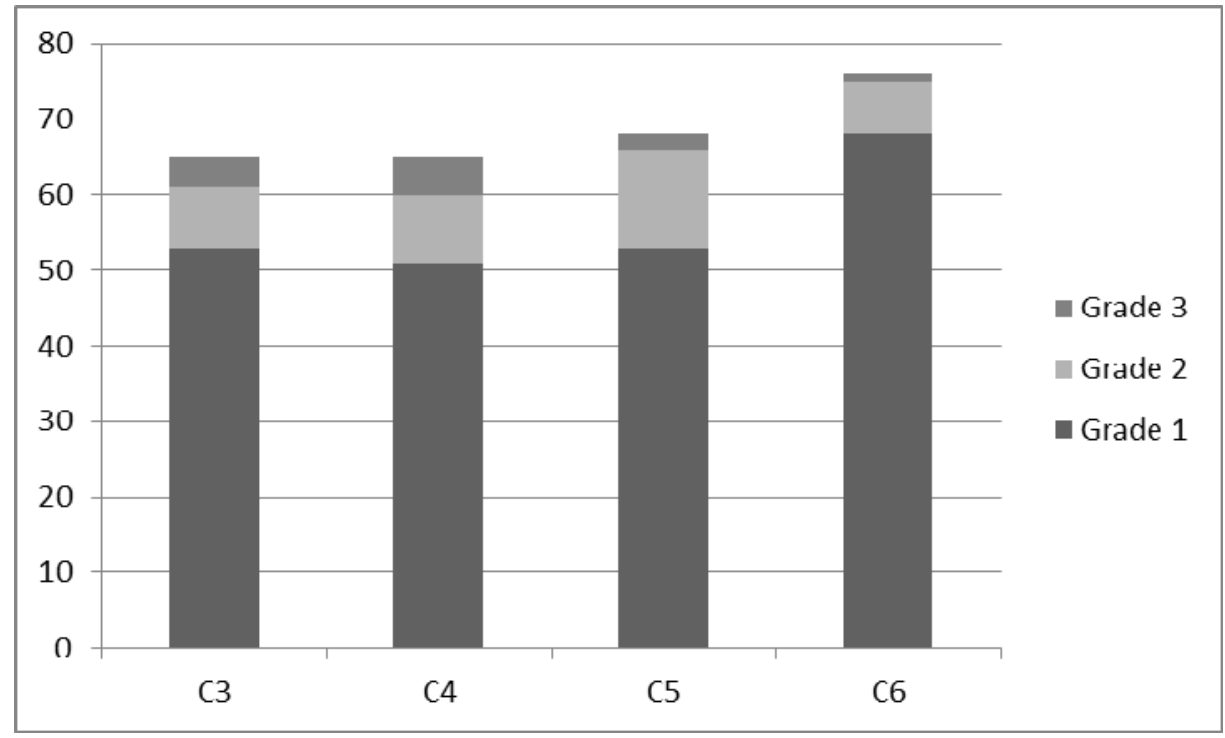

Fig. 1. Position of the cervical pedicle screw at different vertebral levels, observed by postoperative CT. Grade 1 (no perforation), screw is accurately inserted in the pedicle; Grade 2 (minor perforation), perforation of less than $50 \%$ of screw diameter; Grade 3 (major perforation), perforation of $50 \%$ of screw diameter or more. 
The percentage of total lateral and medial perforations were $76 \%(37 / 49)$ and $24 \%(12 / 49)$, respectively. Grade 3 lateral and medial perforations were observed in 6 and 5 pedicles, respectively (Fig. 2). Grade 2 lateral and medial perforations were observed in 31 and 7 pedicles, respectively (Fig. 3). No vertebral artery tear, spinal cord injury, and nerve root injury were observed.

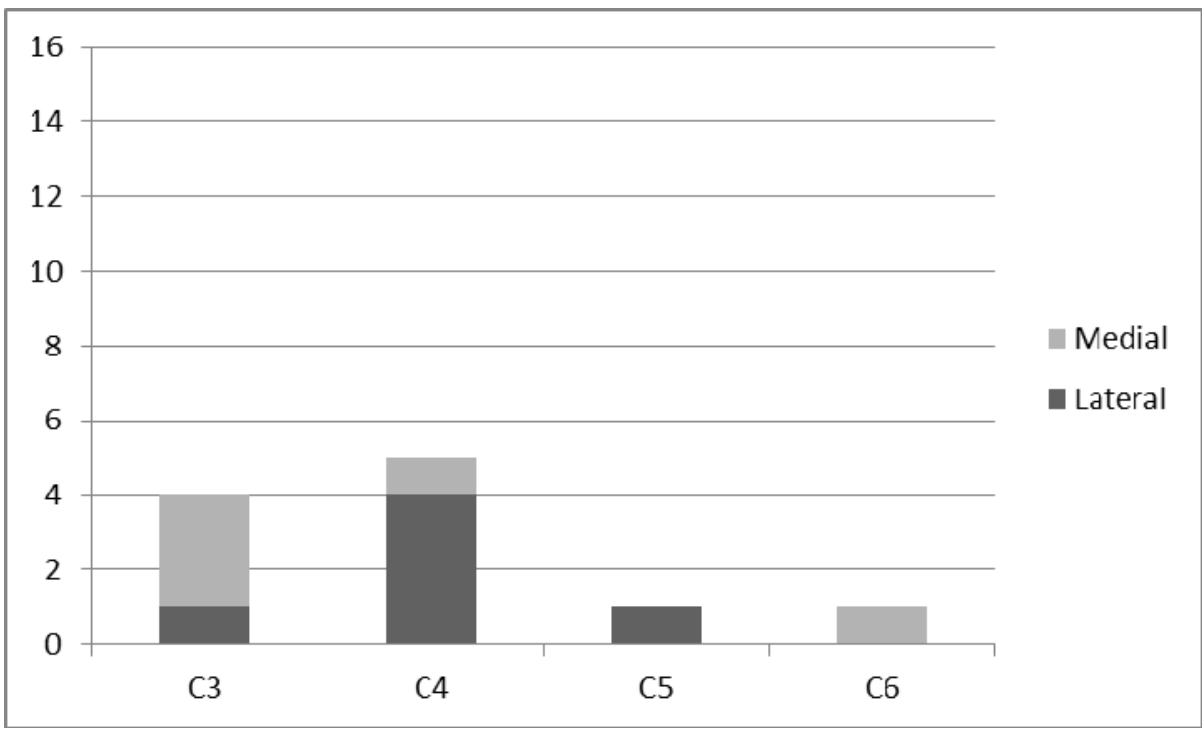

Fig. 2. Direction of grade 3 cervical pedicle screw perforation at different vertebral levels.

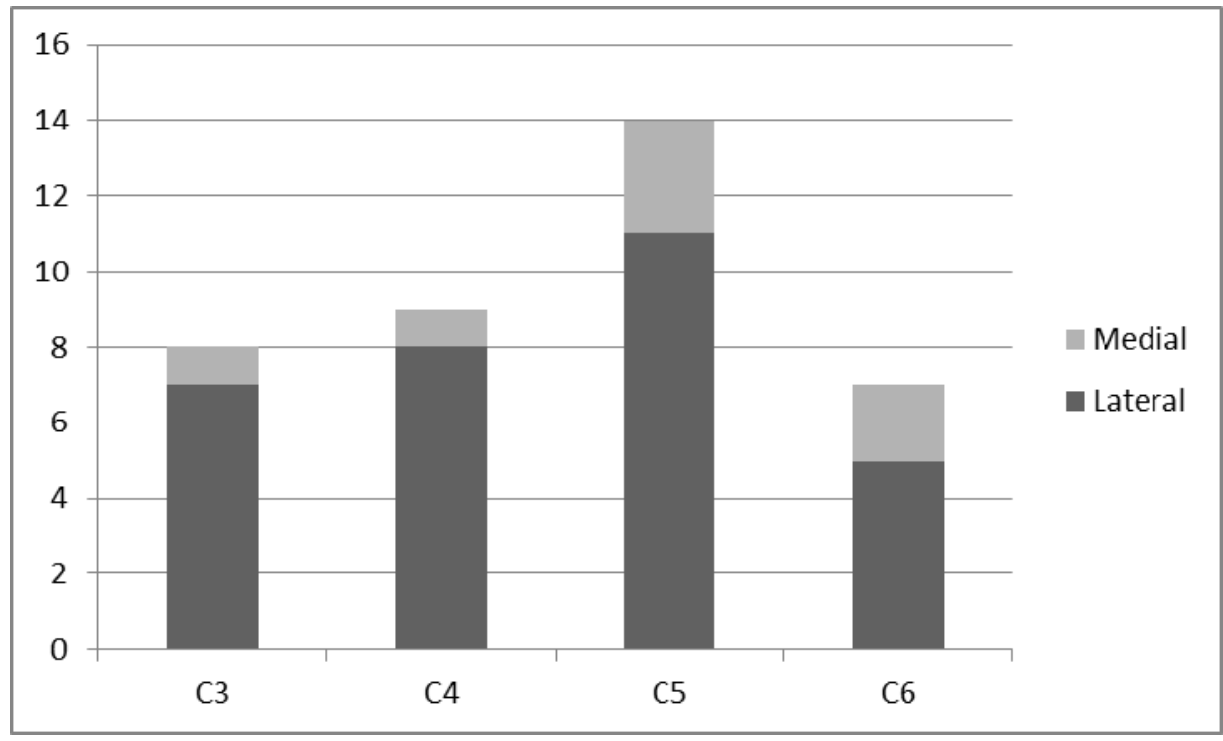

Fig. 3. Direction of grade 2 cervical pedicle screw perforation at different vertebral levels. 


\section{Case report}

67 year-old male with rheumatoid cervical spine. The subject presented with spinal cord compression and instability at the C3-C4 and C4-C5 levels and showed myelopathy (Fig. 4) Laminoplasy and posterior fusion with CPS from C3 to C5 was performed (Fig. 5). Postoperative axial CT indicated the screw insertion status, which was as follows: bilateral C3, grade 2; right side of $\mathrm{C} 4$, grade 3; left side of $\mathrm{C} 4$, grade 2; and bilateral C5, grade 1 (Fig. 6).

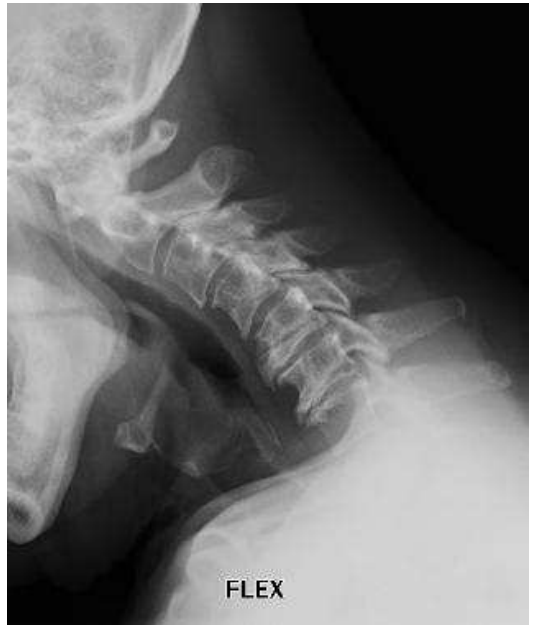

a

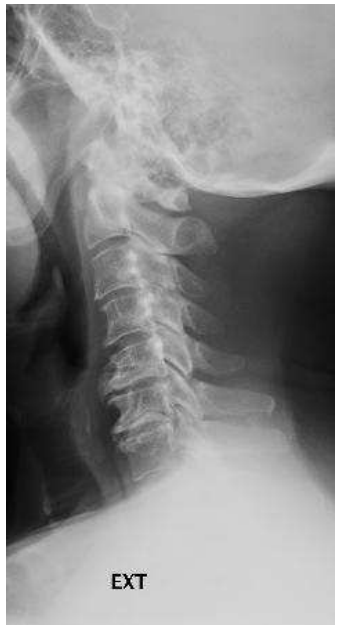

b

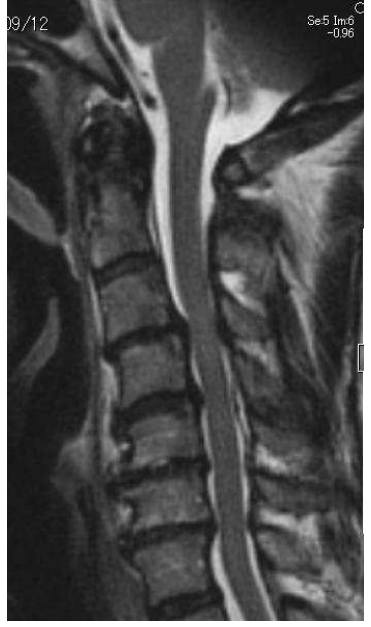

C

Fig. 4. a,b) Preoperative maximum flexion and extension lateral X-ray. Instability was observed at the C3-C4 and C4-C5 levels. c) MRI scan (T2-WI sagittal view). Spinal cord compression was observed at the $\mathrm{C} 3-\mathrm{C} 4$ and $\mathrm{C} 4-\mathrm{C} 5$ levels.
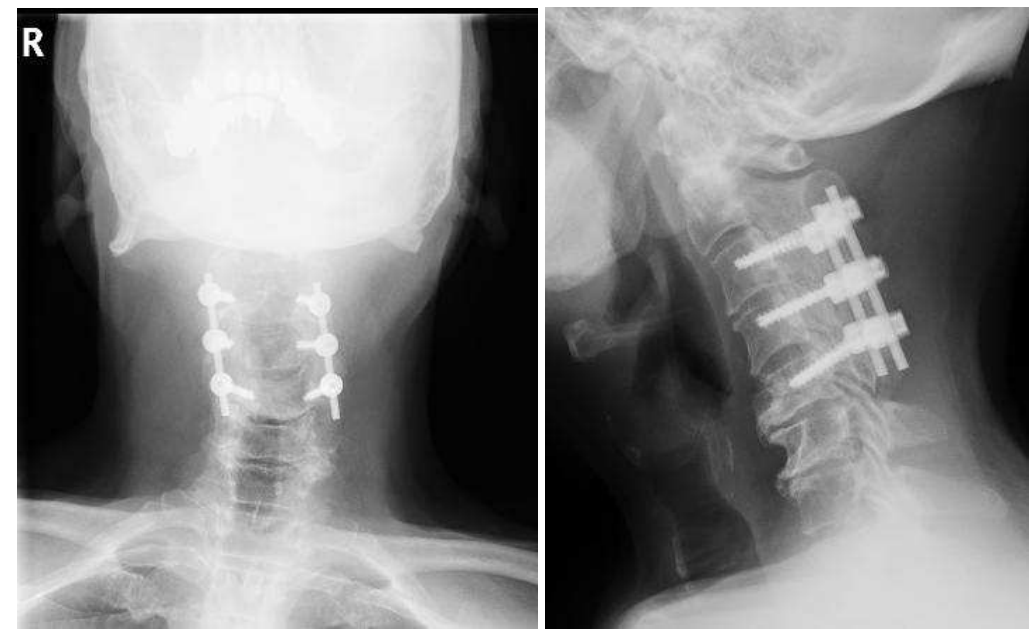

Fig. 5. Laminoplasy and posterior fusion with CPS from C3 to C5 was performed. 


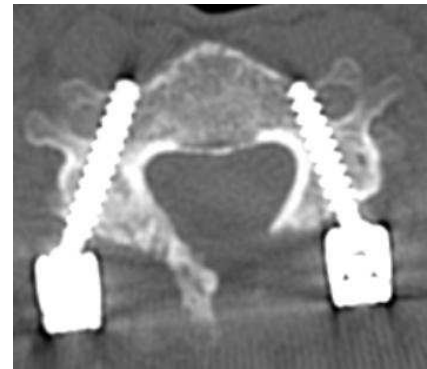

C3

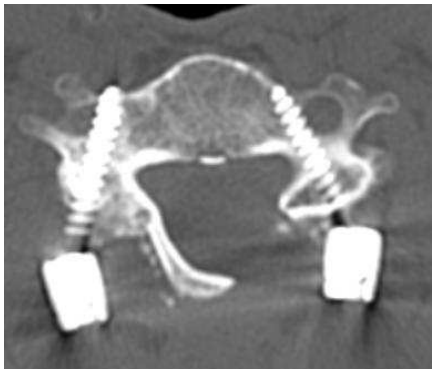

C4

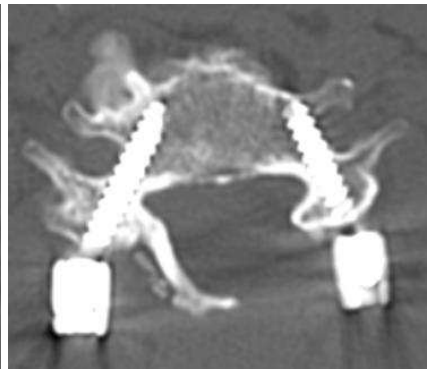

C5

Fig. 6. Postoperative axial CT showed the following screw insertion status: bilateral C3, grade 2; right side of $\mathrm{C} 4$, grade 3; left side of $\mathrm{C} 4$, grade 2; and bilateral $\mathrm{C} 5$, grade 1 .

\section{Discussion}

Cervical pedicle screws can achieve rigid fixation compared to other cervical pedicle fixation methods [13, 14], and enable posterior cervical cord decompression. However, cervical pedicle screw insertion is technically demanding because of the narrow pedicle diameter and the risk of serious neurovascular complications including vertebral artery tear, spinal cord injury, and nerve root injury [15]. Indication of cervical pedicle screw technique is as follows: destructive lesions including RA, DSA, and spine tumor; procedures that include both spinal cord decompression and posterior fusion. For rheumatoid cervical spine, this technique is especially useful because the strong initial fixation eliminates the necessity of postoperative external fixation such as halo vest or collar.

To achieve more accurate and safe pedicle screw insertion, navigation by two-dimensional imaging system or CT has been employed in recent years. In the meta-analysis reported by Tian et al., the accuracy of pedicle screw insertion by CT navigation $(90.76 \%)$ was significantly improved compared to the two-dimensional imaging system (85.48\%) [16]. Our institution employs a CT-based navigation system for the cervical pedicle screw insertion [912]. The result of this paper was that the percentage of major perforations were $4.4 \%$, total perforation rates were $17.9 \%$ for all cervical pedicle screws. Richter et al. [17] reported comparative study of cervical pedicle screw fixation with conventional versus computer assisted surgery (CAS). In their result, pedicle perforation was $8.6 \%$ in conventional group and $3.0 \%$ in CAS group. Richter et al. indeed reported an excellent surgical outcome. The study of Richter et al. involved screw insertion for the upper thoracic vertebrae that have a larger vertebrae width as compared to the C3-C6 vertebrae that we studied, and vertebrae sizes could be larger in German individuals than in Japanese individuals. The reason for the larger perforation rate in our study could have resulted from the presence of a smaller pedicle in Japanese people and the narrow pedicle sizes of C3-C6 vertebrae.

Higher perforation rates for grade 3 (major perforation) were observed for C4 and C3. Furthermore, higher perforation rates for grade 2 and 3 (including minor perforation) were observed for C5, C4, and C3, in this order. For C6, the number of both major and minor perforations was small. Rheinhold et al. [18] measured the mean outer pedicle width for C3C6 in human cadavers (mean age, 85 years), and the values for C3, C4, C5, and C6 were found to be $5.7 \pm 0.4 \mathrm{~mm}, 5.6 \pm 0.6 \mathrm{~mm}, 6.2 \pm 0.6 \mathrm{~mm}$, and $6.7 \pm 0.6 \mathrm{~mm}$, respectively. Yusof 
et al. [19] studied the transverse pedicle diameter of the C2-C7 of the cervical spine in a Malaysian population using computerized tomography (CT) measurements. The mean transverse diameters of the cervical pedicle of C3, C4, C5, and C6 in males were 5.2, 5.1, 5.2, and $5.5 \mathrm{~mm}$, respectively. In females, the mean transverse diameter of the cervical pedicle of C3, C4, C5, and C6 were 4.6, 4.7, 4.9, and 5.2mm, respectively. Our data on CPS perforation supported the results of the abovementioned studies in that pedicles with smaller diameters were found to have a larger number of perforations. The reason for the large number of minor perforations at C5 is unclear. C3 and C4 pedicles are generally narrow and hence, screw insertion is performed carefully. However, C5 is wider than C3 and C4; thus, the surgeon might be less attentive during the screw insertion for $\mathrm{C} 5$, which could contribute to this finding. Therefore, careful attention should be paid with respect to major perforations in the case of the $\mathrm{C} 3$ and $\mathrm{C} 4$ pedicles.

We found that a larger number of minor perforations occurred in the lateral direction than in the medial direction and that many major perforations were observed in the medial direction at the C3 level. During screw insertion in the cervical pedicle, the cortex is thicker in the medial direction and thinner in the lateral direction, and therefore, the CPS is likely to cause perforation in the lateral direction. In this study, perforation occurred in the lateral direction in $76 \%$ of the cases.

The possible causes of perforation of pedicle screw are as follows: Deviation of CT-based navigation system caused from unintentional movement of reference frame during operation etc.; lateral perforation caused by pressure from paravertebral muscle to probe, tap, or screw; narrow osteosclerotic pedicle that has no cancellous bone. To avoid perforation under such conditions, countermeasures as follows are required: If the practitioner judges the insertion point or screw direction shown by the navigation system is incorrect, intraoperative x-ray image or fluoroscopy shall be used. If screw direction could not be set sufficiently in the medial orientation, prepare a skin incision externally and insert probe, tap, and screw from the incision. In the case of narrow or osteosclerotic pedicle, skip the pedicle or change the fixation method to lateral mass screw, sublaminar cable, or other.

\section{Conclusions}

Major perforations were mostly observed in C4 and C3 pedicles. However, the number of C5 pedicle perforations was as large as C4 or C3 pedicle perforations when the total perforations, i.e., both major and minor perforations, were considered. The perforation rate of C6 pedicle was lesser than that for pedicles from C3 to C5. The major perforation rate for lateral and medial perforations was comparable. CPS insertion from C3 to C5 should be performed with extreme caution even under the CT-based navigation system.

\section{References}

[1] Abumi K, Itoh H, Taneichi H, Kaneda K. Transpedicular screw fixation for traumatic lesions of the middle and lower cervical spine: Description of the techniques and preliminary report. J Spinal Disord 1994;7:19-28.

[2] Janneret B, Gebhard JS, Magerl F. Transpedicular screw fixation of articular mass fractureseparation: Results of an anatomical study and operative technique. J Spinal Disord 1994;7:222-9. 
[3] Abumi K, Kaneda K. Pedicle screw fixation for nontraumatic lesions of the spine. Spine 1997;22:1853-63.

[4] Abumi K, Kaneda K, Shono Y, Fujiyama M. One-stage posterior decompression and reconstruction of the cervical spine by using pedicle screw fixation systems. J Neurosurg 1999 ;90:19-26.

[5] Jones EI, Heller JG, Silcox DH, Hutton WC. Cervical pedicle screws versus lateral mass screws: Anatomic feasibility and biomechanical comparison. Spine 1997; 22:977-82.

[6] Kotani Y, Cunningham BW, Abumi K, McAfee PC. Biomechanical analysis of cervical stabilization systems: An assessment of transpedicular screw fixation in the cervical spine. Spine 1994;19:2529-39.

[7] Karaikovic EE, Kunakornsawat S, Daubs MD, Madsen TW, Gaines RW Jr. Surgical anatomy of the cervical pedicles: Landmarks for posterior cervical pedicle entrance localization. J Spinal Disord 2000; 13: 63-72.

[9] Takahashi J, Shono Y, Nakamura I, et al. Computer-assisted screw insertion for cervical disorders in rheumatoid arthritis. Eur Spine J 2007;16:485-494.

[10] Yuzawa Y, Kamimura M, Nakagawa H, et al. Surgical treatment with instrumen- tation for severely destructive spondyloarthropathy of cervical spine. J Spinal Disord Tech 2005; 18: 23-8.

[11] Ogihara N, Takahashi J, Hirabayashi H, Hashidate H, Kato H. Long-term results of computer-assisted posterior occipitocervical reconstruction.World Neurosurg. 2010; 73: 722-8.

[12] Uehara M, Takahashi J, Hirabayashi H, Hashidate H, Ogihara N, Mukaiyama K, Ikegami S, Kato H. Perforation rates of cervical pedicle screw insertion by disease and vertebral level. Open Orthop J. 2010; 4: 142-6.

[13] Jones EI, Heller JG, Silcox DH, Hutton WC. Cervical pedicle screws versus lateral mass screws: Anatomic feasibility and biomechanical comparison. Spine 1997; 22:977-82.

[14] Kotani Y, Cunningham BW, Abumi K, McAfee PC. Biomechanical analysis of cervical stabilization systems: An assessment of transpedicular screw fixation in the cervical spine. Spine 1994;19:2529-39.

[15] Karaikovic EE, Kunakornsawat S, Daubs MD, Madsen TW, Gaines RW Jr. Surgical anatomy of the cervical pedicles: Landmarks for posterior cervical pedicle entrance localization. J Spinal Disord 2000;13:63-72.

[16] Tian NF, Xu HZ. Image-guided pedicle screw insertion accuracy: a meta-analysis. Int Orthop. 2009; 33:895-903.

[17] Richter M, Cakir B, Schmidt R. Cervical pedicle screws: conventional versus computerassisted placement of cannulated screws. Spine 2005;30:2280-7.

[18] Reinhold M, Magerl F, Rieger M, Blauth M. Cervical pedicle screw placement: feasibility and accuracy of two new insertion techniques based on morphometric data. Eur Spine J. 2007 ; 16:47-56.

[19] Yusof MI, Ming LK, Abdullah MS, Yusof AH. Computerized tomographic measurement of the cervical pedicles diameter in a Malaysian population and the feasibility for transpedicular fixation. Spine 2006;31(8):E221-4. 


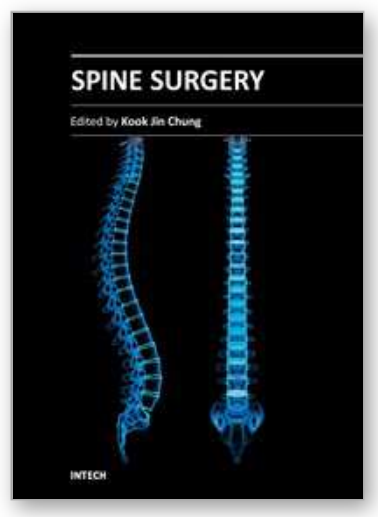

\author{
Spine Surgery \\ Edited by Dr. Kook Jin Chung
}

ISBN 978-953-51-0469-8

Hard cover, 148 pages

Publisher InTech

Published online 28, March, 2012

Published in print edition March, 2012

"Spine Surgery" is an authoritative and didactic textbook on the various fields of spine. It is written by many authors, internationally honorable experts to share their opinions with you. The chapters cover from anatomy of spine, spinal imaging technique, biology of spine, bone graft substitute, minimally invasive spinal surgery to even spinal deformity. It has many up to date results to help readers including university graduate students, medical instrumentation developers, and medical professionals including orthopaedic and neurosurgeons, rehabilitative professionals. The readers are provided with precious information and valuable guide in your daily practice.

\title{
How to reference
}

In order to correctly reference this scholarly work, feel free to copy and paste the following:

Jun Takahashi, Hiroki Hirabayashi, Hiroyuki Hashidate, Nobuhide Ogihara, Keijiro Mukaiyama, Syuugo Kuraishi, Masayuki Shimizu, Masashi Uehara and Hiroyuki Kato (2012). Perforation Rates of Cervical Pedicle Screw Inserted from C3 to C6 - A Retrospective Analysis of 78 Patients over a Period 5 of 14 Years -, Spine Surgery, Dr. Kook Jin Chung (Ed.), ISBN: 978-953-51-0469-8, InTech, Available from:

http://www.intechopen.com/books/spine-surgery/perforation-rates-of-cervical-pedicle-screw-inserted-from-c3to-c6-a-retrospective-analysis-of-78-pa

\section{INTECH}

open science | open minds

\author{
InTech Europe \\ University Campus STeP Ri \\ Slavka Krautzeka 83/A \\ 51000 Rijeka, Croatia \\ Phone: +385 (51) 770447 \\ Fax: +385 (51) 686166 \\ www.intechopen.com
}

\author{
InTech China \\ Unit 405, Office Block, Hotel Equatorial Shanghai \\ No.65, Yan An Road (West), Shanghai, 200040, China \\ 中国上海市延安西路65号上海国际贵都大饭店办公楼 405 单元 \\ Phone: +86-21-62489820 \\ Fax: +86-21-62489821
}


(C) 2012 The Author(s). Licensee IntechOpen. This is an open access article distributed under the terms of the Creative Commons Attribution 3.0 License, which permits unrestricted use, distribution, and reproduction in any medium, provided the original work is properly cited. 